\title{
RBXI/ROCI-SCF E3 ubiquitin ligase is required for mouse embryogenesis and cancer cell survival
}

$$
\text { Lijun Jia and Yi Sun* }
$$

Address: Division of Radiation and Cancer Biology, Department of Radiation Oncology, University of Michigan Comprehensive Cancer Center, 4424B Medical Science-I, 1301 Catherine Street, Ann Arbor, MI 48109, USA

Email: Lijun Jia - lijunjia@umich.edu; Yi Sun* - sunyi@umich.edu

* Corresponding author

Published: 6 August 2009

Cell Division 2009, 4:16 doi:10.1 186/1747-1028-4-16

This article is available from: http://www.celldiv.com/content/4/l/16

(c) 2009 jia and Sun; licensee BioMed Central Ltd.

This is an Open Access article distributed under the terms of the Creative Commons Attribution License (http://creativecommons.org/licenses/by/2.0), which permits unrestricted use, distribution, and reproduction in any medium, provided the original work is properly cited.
Received: 24 July 2009

Accepted: 6 August 2009

\begin{abstract}
RBXI (also known as ROCl) is a RING subunit of SCF (纤 I, Cullins, F-box proteins) E3 ubiquitin ligases, required for SCF to direct a timely degradation of diverse substrates, thereby regulating numerous cellular processes under both physiological and pathological conditions. Previous studies have shown that RBXI is essential for growth in yeast, Caenorhabditis elegans and Drosophila. The role of RBXI in mouse development and in regulation of cancer cell survival was unknown. Our recent work demonstrated that RBXI is an essential gene for mouse embryogenesis, and targeted disruption of RBXI causes embryonic lethality at E7.5 due to hypoproliferation as a result of p27 accumulation. We also showed that RBXI is overexpressed in a number of human cancers, and siRNA silencing of RBXI caused cancer cell death as a result of sequential induction of G2-M arrest, senescence and apoptosis. These findings reveal a physiological role of RBXI during mouse development and a pathological role for the survival of human cancer cells. Differential outcomes between normal (growth arrest) and cancer cells (cell death) upon RBXI disruption/silencing suggest RBXI as a valid anticancer target.
\end{abstract}

\section{Comments on:}

Tan M, Davis SW, Saunders TL, Zhu Y, Sun Y. RBXI/ROCI disruption results in early embryonic lethality due to proliferation failure, partially rescued by simultaneous loss of p27. Proc Natl Acad Sci USA. 2009; 106:6203-6208

Jia L, Soengas MS, Sun Y. ROCI/RBXI E3 ubiquitin ligase silencing suppresses tumor cell growth via sequential induction of G2-M arrest, apoptosis, and senescence. Cancer Res. 2009; 69:4974-82

\section{Introduction}

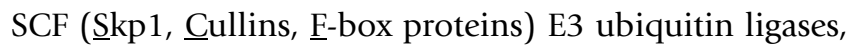
consist of $\underline{S} k p 1$, Cullins, F-box proteins, and the RING domain containing protein RBX1/ROC1 or its family member RBX2/ROC2/SAG. By promoting degradation of many short-lived proteins, including cell cycle regulators, transcription factors and signal transducers, RBX1-SCF E3 ligases regulate many biological processes. As an essential subunit of the SCF E3 ligase complex, RBX1, is evolutionarily conserved from plants to mammals with multiple family members in each species [1]. Human RBX1 gene consists of five exons and four introns and encodes a 108 amino acids-containing protein with a RING-H2 finger domain $(\mathrm{C} 3 \mathrm{H} 2 \mathrm{C} 3)$ at the $\mathrm{C}$-terminus, which is required 
for zinc ion binding and ubiquitin ligation. Human RBX1 is ubiquitously expressed in human tissues with the highest expression in heart, skeleton muscle, kidney and placenta [2]. Structurally, RBX1 binds to the C-terminus of cullin-1 via its N-terminus and to an E2 ubiquitin conjugating enzyme via its C-terminal RING domain. RBX1/ Cullin-1 complex catalyzes the ubiquitin transfer from E2 to the substrates which are recognized by different F-box proteins, linked to the N-terminus of cullin-1 via an adaptor protein, Skp1 [3] (Fig 1).

RBX1 binds to all seven cullin family members, including cullin- $1,-2,-3,-4 \mathrm{~A},-4 \mathrm{~B},-5$ and -7 [4]. By binding to and interaction with different cullins and cullin-associated proteins, RBX1, as an active RING component of the largest family of E3 ubiquitin ligases, plays an essential role in regulation of diverse biological processes by promoting the degradation of different protein substrates. Table 1 lists some known substrates targeted by different RBX1cullins complexes. Over 350 potential RING-cullin substrates were recently identified by a global protein stability profiling analysis [5]. Further characterization and validation of these substrates will broaden our understanding of how RBX1-cullin-based E3 ligases regulate cellular processes under physiological and pathological conditions.

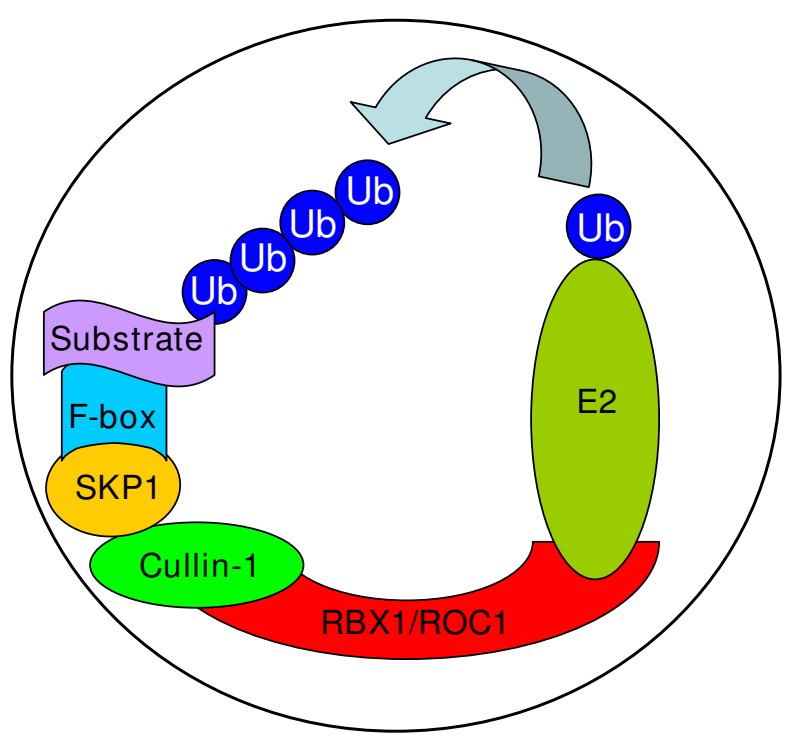

Figure I

Substrate ubiquitination by RBXI-SCF E3 ubiquitin

ligase: Cullin-I at its N-terminus binds to Skpl and an F-box protein, which recognizes protein substrates, and at its $C$ terminus binds to RBXI. RBXI, on the other hand, binds to Cullin-I using its $\mathrm{N}$-terminus and an E2 ubiquitin conjugating enzyme using its C-terminal RING domain. Together, RBXIcullin-I catalyzes the ubiquitin transfer from E2 to protein substrates.

\section{Discussion}

\section{RBXI in development}

RBX1-cullin complexes control the proteolysis of numerous substrates related to cell cycle progression, cell growth and cell death, suggesting that RBX1 may play an important role in development. Indeed, RBX1 is an essential gene in a number of species. In yeast, deletion of Hrt1, the yeast homologue of RBX1, via genetic manipulation, causes yeast death, which can be rescued by human RBX1 or RBX2/SAG [6-8]. In Caenorhabditis elegans, RBX1 is also crucial for cell cycle progression and chromosome metabolism, as evidenced by severe defects in meiosis, mitotic chromosomal condensation and segregation, and cytokinesis upon siRNA knockdown [9]. In Drosophila, ROC1a, the drosophila homologue of RBX1 is required for cell proliferation and embryo development, and deletion of ROC1a results in animal death [10]. In mouse, the level of RBX1 mRNA was regulated during embryonic development with the strongest expression at embryonic day 7 (E7), followed by a progressive decrease [11]. However, the physiological role of RBX1 in mouse development has not been previously characterized.

Most recently, we characterized the in vivo physiological function of RBX1 during mouse development using a conventional knockout study [12]. We found that homozygous disruption of mouse $R B X 1$ via a gene trap strategy causes embryonic lethality at E7.5 as a result of reduced proliferation, but not enhanced apoptosis. Mechanistic studies revealed that $R B X 1$ disruption induces significant accumulation of p27, a cyclin dependent kinase inhibitor, normally not expressed in early embryos. The p27 accumulation was further observed in mouse embryonic fibroblasts (MEF) or mouse embryonic stem cells (ESC) with RBX1 heterozygous background. In $R B X 1^{+/-}$ MEF cells, p27 accumulation is associated with growth retardation and G1 arrest. Causal involvement of p27 accumulation in early death of $R B X 1$-deficient embryos was clearly demonstrated by a rescue experiment in which simultaneous loss of p27 extends the life span of RBX1deficient embryos from E6.5 to E9.5 [12]. Our study demonstrates that the in vivo physiological function of RBX1 is to ensure cell proliferation by preventing p27 accumulation during the early stage of embryonic development (Fig $2 \mathrm{~A})$. The fact that p27 loss cannot completely rescue RBX1-deficient embryos indicates that accumulation of other RBX1 substrates upon RBX1 disruption is detrimental to embryonic development beyond E9.5 (Fig 2A). A future challenge will be to define these physiologically relevant substrates to broaden our understanding of the in vivo physiological function of RBX1 in the later stages of mouse embryogenesis.

Functional characterization using various model systems from yeast to mouse clearly demonstrated that $R B X 1$ is an 
Table I: RBXI-Cullins E3 ubiquitin ligases and their substrates in mammals

\begin{tabular}{|c|c|c|}
\hline Name & Substrates & References \\
\hline RBXI/Cullin-I/SKPI/F-Box proteins & $\begin{array}{l}\text { e.g. } \mathrm{P} 2 \mathrm{I}, \mathrm{p} 27, \mathrm{p} 57, \mathrm{Cyclins} \mathrm{A} / \mathrm{D} / \mathrm{E}, \mathrm{E} 2 \mathrm{FI}, \mathrm{Cdc} 25 \mathrm{~A} / \mathrm{B}, \mathrm{PDCC} 4, \mathrm{FOXO} \text {, Myc, } \mathrm{p} 53 \text {, } \\
\text { c-Jun, Notch } 1 / 4, \mathrm{I} \mathrm{B}, \beta-\text {-Catenin, Orc I, and many more. For near complete list, } \\
\text { see cited references }\end{array}$ & {$[14,25,26]$} \\
\hline RBXI/Cullin-2/Elongin BC/VHL & e.g. HIF- $\alpha$, TEL-JAK2 & {$[27,28]$} \\
\hline RBXI/Cullin-3/BTB-domain proteins & $\begin{array}{l}\text { e.g. MEl-I, Dishevelled (Dsh), Nrf2, RhoBTB2, topoisomerasel-DNA complex, } \\
\text { and caspase } 8\end{array}$ & [29-36] \\
\hline RBXI/Cullin-4A/DDBI & e.g. p53, TSC2, Cdt I, c-Jun and Merlin & [37-45] \\
\hline RBXI/Cullin-5/elongin BC/BC-box proteins/SOCS & e.g. Disabled-I (Dabl) & {$[46]$} \\
\hline RBXI/Cullin-7/SKPI/Fbw8 & e.g. Insulin receptor substrate I (IRS-I) & [47] \\
\hline
\end{tabular}

essential gene for growth and development. Interestingly, some similarity and difference exist between the species with more than one family member of RBX1. For example, death phenotype induced by disruption of ROC1a in Drosophila or of $R B X 1$ in mouse in the presence of their family member $R O C 2$ or $R B X 2[10,12,13]$ clearly indicated that these two RBX1 family members are not functionally redundant and are likely to target different sets of substrates during embryonic development. On the other hand, the mechanisms responsible for reduced proliferation as a result of ROC1a/RBX1 disruption seem different between Drosophila and mouse. In Drosophila, disruption of ROC1a, causes lethality due to proliferation failure as a result of accumulation of $\mathrm{Ci}$ (a Drosophila ortholog of mouse Gli2), a transcription factor that regulates Hedgehog signaling [10]. Whereas in mouse, disruption of RBX1 does not affect the levels of Gli2, but causes p27 accumulation to suppress proliferation [12]. Furthermore, although RBX1-p27 double null embryos at E9.5 are smaller than wild type littermates, no enhanced apoptosis was detected using the TUNEL assay (unpublished data). Thus, during mouse embryogenesis, RBX1 disruption appears not to induce apoptosis. These observations in normal tissues are strikely different from those seen in human cancer cells (see below) in which RBX1 silencing induces significant levels of apoptosis and senescence.

\section{RBXI in human cancer cell survival}

RBX1-SCF E3 ubiquitin ligases regulate numerous cellular processes. It is not surprising that their dysfunction is associated with a variety of diseases including cancer [14]. For example, an oncogenic F-box protein Skp2, which promotes p27 degradation, is overexpressed in a number of human cancers [15], whereas a tumor suppressive Fbox protein FBW7, which promotes the degradation of several proto-oncogenes, including c-Jun, c-Myc, cyclin E and mTOR undergoes numerous cancer-associated muta- tions [16]. To define potential roles of RBX1 in human cancers, we recently measured expression of RBX1 in human primary cancer tissues and in cancer cell lines with different tissue origins. We found that RBX1 is overexpressed in a number of human primary cancer tissues, including carcinoma of lung, liver, breast, colon, and ovary, and in many cancer cell lines [17]. We then determined potential biological consequences of reducing RBX1 levels via siRNA silencing. Significantly, RBX1 knockdown inhibited the growth of several human cancer cell lines by sequential induction of G2-M arrest, senescence and apoptosis. Further characterization revealed that G2-M arrest is associated with accumulation of 14-3$3 \sigma$ and down-regulation of cyclin B1 and Cdc2, whereas apoptosis is associated with modest accumulation of PUMA and significant reduction of Bcl-2, Mcl-1, and survivin. Interestingly, senescence is p53/p21- and p16/pRBindependent [17]. Recently a shRNA library-based functional genomic screen also identified $R B X 1$ as a growth essential gene in a number of human cancer cell lines, although no characterization was further pursued [18].

Mechanistic studies revealed that RBX1 silencing triggers DNA damage response at the early stage, as demonstrated by induced phosphoralytion of H2AX, Chk1 and Chk2 [17] (and unpublished data), which eventually leads to G2-M arrest, followed by apoptosis and senescence. We hypothesize that either or both sets of RBX1 substrates, which start to accumulate upon RBX1 silencing, are likely involved in the process, leading to phenotypic changes. The first set includes oncogenes (e.g. c-Myc, c-Jun, cyclin $\mathrm{E} / \mathrm{D})$, since oncogene activation triggers DNA damage response to induce senescence and apoptosis under certain circumstances $[19,20]$. The second set of RBX1-cullin substrates could be DNA replication proteins, such as Orc1 and Cdt- 1 , since the accumulation of DNA replication proteins (e.g. Cdt-1) induces DNA rereplication stress and 


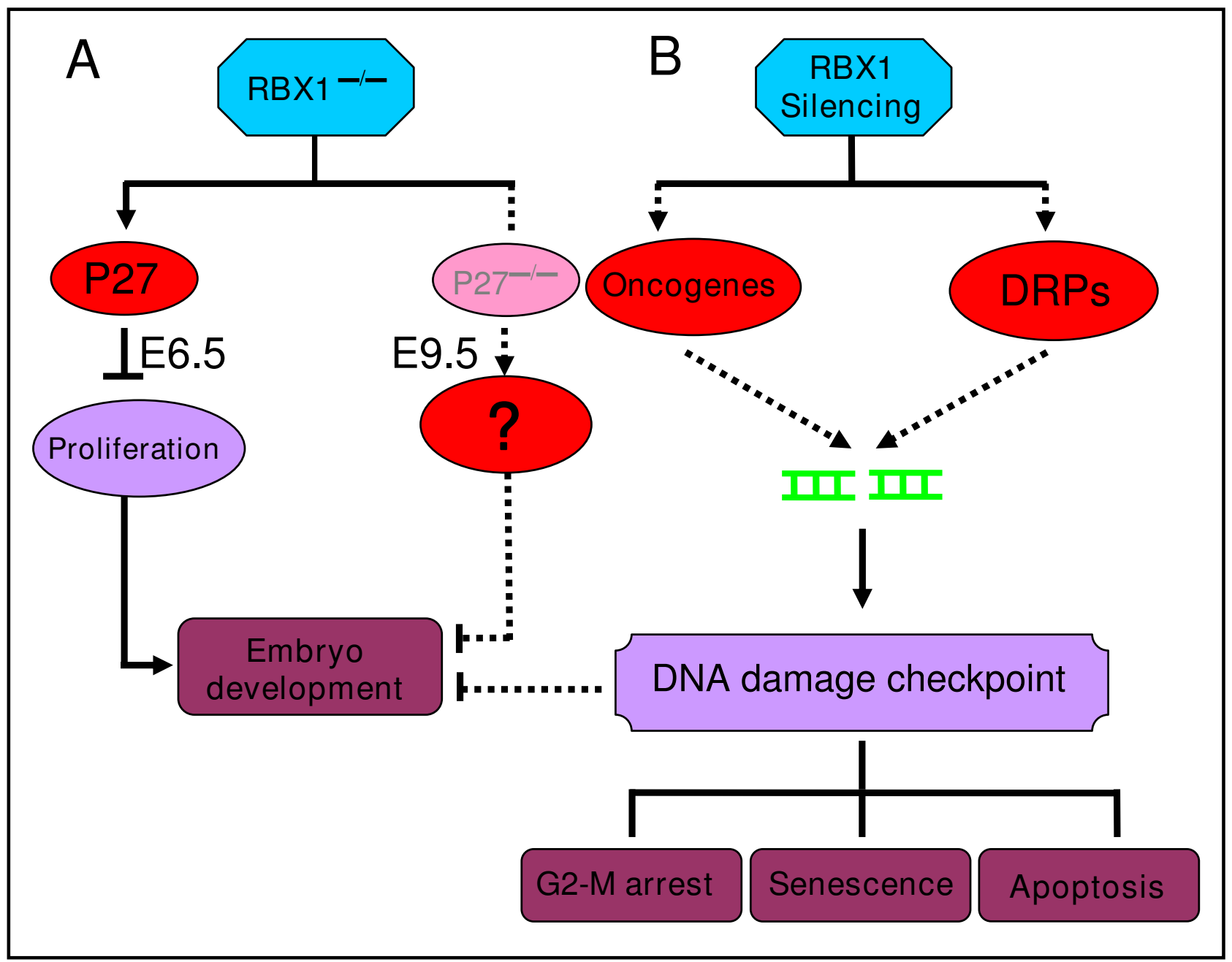

\section{Figure 2}

A working model for RBXI targeting. (A) In mouse embryos. RBXI disruption in mouse induces early embryonic lethality due to reduced proliferation as a result of p27 accumulation. Simultaneous deletion of p27 restores cell proliferation and causes a partial rescue of embryonic death by extending the embryo's life from E6.5 to E9.5. It is unclear, at the present time, if abnormal DNA damage response is involved in later stage death of RBXI/p27 double null embryos. (B) In human cancer cells: RBXI silencing triggers DNA damage response and checkpoint controls via modulating the levels of oncogenes or DNA replication proteins (DRPs), leading to activation of multiple cell killing pathways, including G2-M arrest, senescence and apoptosis.

triggers DNA damage [21] (Fig 2B). Our laboratory is currently testing the hypothesis to further elucidate the mechanism(s) by which RBX1 silencing induces cancer cell killing via induction of G2-M arrest, senescence and apoptosis.

It is rather clear that the mechanism responsible for early embryonic lethality upon RBX1 disruption is quite different from that responsible for cancer cell killing upon RBX1 silencing, although it is not a typically paired com- parison. Nevertheless, in mouse, RBX1 knockout leads to p27 accumulation, reduced proliferation and prolonged G1 arrest, whereas in human cancer cells, p27 accumulation and G1 arrest were not observed upon RBX1 silencing [17]. Future studies should be directed to determine if the altered DNA damage response commonly seen in cancer cells after RBX1 silencing can also be observed in RBX1p27 double null embryos and if so, its contribution to the embryonic lethality in the later stages of development (Fig 2, crosstalk between panel A and B). 


\section{Conclusion}

The findings from our laboratory demonstrated that RBX1 is an essential gene not only for mouse development but also for human cancer cell survival. The fact that RBX1 is overexpressed in a number of human cancers suggests that abnormal regulation of RBX1 is involved either in human carcinogenesis or in the maintenance of the cancer cell phenotype. Differential response to RBX1 disruption/ silencing between normal tissues (reduced proliferation, but no induction of apoptosis during mouse embryogenesis) and cancer cells (enhanced cell killing) may provide a reasonable therapeutic window for cancer cell-specific killing via RBX1 targeting. Thus, future development of siRNA-based therapy by RBX1 silencing or small molecule inhibitors against RBX1 E3 ubiquitin ligases may hold great promise for the treatment of human cancer [22-24].

\section{Acknowledgements}

This work is supported by the National Cancer Institute grants CA I I I554 and CAII 6982 to YS.

\section{References}

I. Sun $Y$, Tan M, Duan H, Swaroop M: SAG/ROC/Rbx/Hrt, a zinc RING finger gene family: molecular cloning, biochemical properties, and biological functions. Antioxid Redox Signal 200 I, 3:635-650.

2. Swaroop M, Gosink M, Sun Y: SAG/ROC2/Rbx2/Hrt2, a component of SCF E3 ubiquitin ligase: genomic structure, a splicing variant, and two family pseudogenes. DNA Cell Biol 200I, 20:425-434.

3. Zheng N, Schulman BA, Song L, et al.: Structure of the Cull-RbxISkp I-F boxSkp2 SCF ubiquitin ligase complex. Nature 2002, 4l 6:703-709.

4. Ohta T, Michel J, Xiong Y: Association with cullin partners protects ROC proteins from proteasome-dependent degradation. Oncogene 1999, 18:6758-6766.

5. Yen HC, Elledge S]: Identification of SCF ubiquitin ligase substrates by global protein stability profiling. Science 2008 , 322:923-929.

6. Ohta T, Michel J, Schottelius AJ, Xiong Y: ROCI, a homolog of APCII, represents a family of cullin partners with an associated ubiquitin ligase activity. Mol Cell I999, 3:535-54I.

7. Seol JH, Feldman RMR, Zachariae WZ, et al.: Cdc53/cullin and the essential Hrt I RING-H2 subunit of SCF define a ubiquitin ligase module that activates the E2 enzyme Cdc34. Genes \& Dev 1999, I3:1614-1626.

8. Swaroop M, Wang Y, Miller P, et al.: Yeast homolog of human SAG/ROC2/Rbx2/Hrt2 is essential for cell growth, but not for germination: Chip profiling implicates its role in cell cycle regulation. Oncogene 2000, 19:2855-2866.

9. Sasagawa $Y$, Urano T, Kohara $Y$, Takahashi H, Higashitani A: Caenorhabditis elegans RBXI is essential for meiosis, mitotic chromosomal condensation and segregation, and cytokinesis. Genes Cells 2003, 8:857-872.

10. Noureddine MA, Donaldson TD, Thacker SA, Duronio RJ: Drosophila Rocla encodes a RING-H2 protein with a unique function in processing the $\mathrm{Hh}$ signal transducer $\mathrm{Ci}$ by the SCF E3 ubiquitin ligase. Dev Cell 2002, 2:757-770.

II. Perin JP, Seddiqi N, Charbonnier F, et al.: Genomic organization and expression of the ubiquitin-proteasome complex-associated protein Rbx I/ROCI/Hrt I. Cell Mol Biol I999, 45: I I 3 I- I I 37.

12. Tan M, Davis SW, Saunders TL, Zhu Y, Sun Y: RBXI/ROCI disruption results in early embryonic lethality due to proliferation failure, partially rescued by simultaneous loss of p27. Proc Natl Acad Sci USA 2009, 106:6203-6208.

13. Donaldson TD, Noureddine MA, Reynolds PJ, Bradford W, Duronio $\mathrm{RJ}$ : Targeted disruption of Drosophila Roclb reveals functional differences in the Roc subunit of Cullin-dependent E3 ubiquitin ligases. Mol Biol Cell 2004, I 5:4892-4903.
14. Nakayama KI, Nakayama K: Ubiquitin ligases: cell-cycle control and cancer. Nat Rev Cancer 2006, 6:369-38I.

I5. Frescas D, Pagano M: Deregulated proteolysis by the F-box proteins SKP2 and beta-TrCP: tipping the scales of cancer. Nat Rev Cancer 2008, 8:438-449.

16. Welcker M, Clurman BE: FBW7 ubiquitin ligase: a tumour suppressor at the crossroads of cell division, growth and differentiation. Nat Rev Cancer 2008, 8:83-93.

17. Jia L, Soengas MS, Sun Y: ROCI/RBXI E3 ubiquitin ligase silencing suppresses tumor cell growth via sequential induction of G2-M arrest, apoptosis, and senescence. Cancer Res 2009, 69:4974-4982.

18. Schlabach MR, Luo J, Solimini NL, et al:: Cancer proliferation gene discovery through functional genomics. Science 2008, 319:620-624.

19. Schmitt CA: Senescence, apoptosis and therapy - cutting the lifelines of cancer. Nat Rev Cancer 2003, 3:286-295.

20. Wahl GM, Carr AM: The evolution of diverse biological responses to DNA damage: insights from yeast and p53. Nat Cell Biol 200I, 3:E277-286.

21. Liu E, Lee AY, Chiba T, Olson E, Sun P, Wu X: The ATR-mediated $S$ phase checkpoint prevents rereplication in mammalian cells when licensing control is disrupted. J Cell Biol 2007, I 79:643-657.

22. Nalepa G, Rolfe M, Harper JW: Drug discovery in the ubiquitinproteasome system. Nat Rev Drug Discov 2006, 5:596-6I3.

23. Sun $Y$ : Targeting E3 ubiquitin ligases for cancer therapy. Cancer Biol Therapy 2003, 2:623-629.

24. Sun Y: E3 ubiquitin ligases as cancer targets and biomarkers. Neoplasia 2006, 8:645-654.

25. Petroski MD, Deshaies RJ: Function and regulation of cullinRING ubiquitin ligases. Nat Rev Mol Cell Biol 2005, 6:9-20.

26. Skaar JR, D'Angiolella V, Pagan JK, Pagano M: SnapShot: F Box Proteins II. Cell 2009, I 37: I 358.

27. Maxwell PH, Wiesener MS, Chang GW, et al:: The tumour suppressor protein VHL targets hypoxia-inducible factors for oxygen-dependent proteolysis. Nature 1999, 399:271-275.

28. Kamizono S, Hanada T, Yasukawa $H$, et al.: The SOCS box of SOCS-I accelerates ubiquitin-dependent proteolysis of TELJAK2. J Biol Chem 200I, 276: I 2530-I2538.

29. Furukawa M, He YJ, Borchers $C$, Xiong $Y$ : Targeting of protein ubiquitination by BTB-Cullin 3-RocI ubiquitin ligases. Nat Cell Biol 2003, 5:100I-1007.

30. Furukawa M, Xiong Y: BTB protein Keap I targets antioxidant transcription factor Nrf2 for ubiquitination by the Cullin 3RocI ligase. Mol Cell Biol 2005, 25: I62-I7I.

31. Pintard L, Willis JH, Willems A, et al:: The BTB protein MEL-26 is a substrate-specific adaptor of the CUL-3 ubiquitin-ligase. Nature 2003, 425:31 I-316.

32. Angers S, Thorpe CJ, Biechele TL, et al:: The KLHLI2-Cullin-3 ubiquitin ligase negatively regulates the Wnt-beta-catenin pathway by targeting Dishevelled for degradation. Nat Cell Biol 2006, 8:348-357.

33. Niture SK, Jaiswal AK: Prothymosin-alpha mediates nuclear import of the INrf2/Cul3 RbxI complex to degrade nuclear Nrf2. J Biol Chem 2009, 284: I3856-13868.

34. Jin Z, Li Y, Pitti R, et al.: Cullin3-based polyubiquitination and p62-dependent aggregation of caspase-8 mediate extrinsic apoptosis signaling. Cell 2009, I37:721-735.

35. Wilkins A, Ping Q, Carpenter CL: RhoBTB2 is a substrate of the mammalian Cul3 ubiquitin ligase complex. Genes Dev 2004, I 8:856-86I.

36. Zhang HF, Tomida A, Koshimizu R, Ogiso Y, Lei S, Tsuruo T: Cullin 3 promotes proteasomal degradation of the topoisomerase I-DNA covalent complex. Cancer Res 2004, 64: I I |4-I I 2 I.

37. Nag A, Bagchi S, Raychaudhuri P: Cul4A physically associates with MDM2 and participates in the proteolysis of p53. Cancer Res 2004, 64:8152-8I55.

38. Banks D, Wu M, Higa LA, et al.: L2DTL/CDT2 and PCNA interact with $\mathrm{p} 53$ and regulate $\mathrm{p} 53$ polyubiquitination and protein stability through MDM2 and CUL4A/DDB I complexes. Cell Cycle 2006, 5:1719-1729.

39. Hu J, McCall CM, Ohta T, Xiong Y: Targeted ubiquitination of CDTI by the DDBI-CUL4A-ROCI ligase in response to DNA damage. Nat Cell Biol 2004, 6:1003-1009. 
40. Hu J, Zacharek S, He YJ, et al.: WD40 protein FBW5 promotes ubiquitination of tumor suppressor TSC2 by DDBI-CUL4ROCI ligase. Genes Dev 2008, 22:866-87I.

41. Huang J, Chen J: VprBP targets Merlin to the Rocl-Cul4ADDBI E3 ligase complex for degradation. Oncogene 2008, 27:4056-4064.

42. Wertz IE, O'Rourke KM, Zhang Z, et al.: Human De-etiolated-I regulates c-Jun by assembling a CUL4A ubiquitin ligase. Science 2004, 303:|37|-|374.

43. Jin J, Arias EE, Chen J, Harper JW, Walter JC: A family of diverse Cul4-Ddb/-interacting proteins includes Cdt2, which is required for $\mathbf{S}$ phase destruction of the replication factor Cdtl. Mol Cell 2006, 23:709-72I.

44. Higa LA, Mihaylov IS, Banks DP, Zheng J, Zhang H: Radiation-mediated proteolysis of CDTI by CUL4-ROCI and CSN complexes constitutes a new checkpoint. Nat Cell Biol 2003, 5: $1008-1015$.

45. Zhong W, Feng H, Santiago FE, Kipreos ET: CUL-4 ubiquitin ligase maintains genome stability by restraining DNA-replication licensing. Nature 2003, 423:885-889.

46. Feng L, Allen NS, Simo S, Cooper JA: Cullin 5 regulates Dab I protein levels and neuron positioning during cortical development. Genes Dev 2007, 21:2717-2730.

47. Xu X, Sarikas A, Dias-Santagata DC, et al:: The CUL7 E3 ubiquitin ligase targets insulin receptor substrate I for ubiquitindependent degradation. Mol Cell 2008, 30:403-4I4.

Publish with Bio Med Central and every scientist can read your work free of charge

"BioMed Central will be the most significant development for disseminating the results of biomedical research in our lifetime. "

Sir Paul Nurse, Cancer Research UK

Your research papers will be:

- available free of charge to the entire biomedical community

- peer reviewed and published immediately upon acceptance

- cited in PubMed and archived on PubMed Central

- yours - you keep the copyright 